\title{
HÁ FILOSOFIA(S) DA(S) SEXUALIDADE(S)?
}

RESUMO: O presente artigo pretende explicitar a necessidade e a possibilidade de falarmos de filosofias das sexualidades como um influxo importante na renovação dos cursos e dos debates em filosofia, principalmente em universidades públicas do Brasil. Para tanto, partiremos (I) das definições etimológicas e conceituais do termo "sexualidade", (II) a relação entre o espaço acadêmico, estudos de sexualidade, a atividade filosófica e o papel do senso comum, (III) um interlúdio sobre as diferenças entre filosofia no, a partir, e do Brasil para que possamos pensar as especificidades nacionais, e finalmente (IV) uma introdução de alguns agentes brasileiros que contribuem incessantemente ao tema.

Palavras-chave: Corpo; Epistemologia; Gênero-Sexualidade-Sexo; História da Filosofia; Política.

\section{THERE ARE PHILOSOPHY (S) OF SEXUALITY (IES)?}

ABSTRACT: This article intends to explain the necessity and the possibility of discussing philosophies of sexualities as an important influence in the renewal of courses and debates in philosophy, especially in universally peripheral universities such as public universities in Brazil. To do so, we will depart from the etymological and conceptual definitions of the term "sexuality", (II) the relationship between academic space, studies of sexuality, philosophical activity and the role of common sense, (III) an interlude on the differences between philosophy in, from and of Brazil so that we can think about the national specificities and finally, (V) an introduction of some Brazilian agents that contribute incessantly to the theme.

Keywords: Body; Epistemology; Gender-Sexuality-Sex; History of Philosophy; Politic.

\section{INTRODUÇÃO}

Ao contrário da imagem midiatizada para e no exterior o tema da sexualidade no Brasil é permeado por tabus no dia-a-dia e nevralgicamente entrelaçados nas estruturas de classe, raça, gênero, intercomunicação e no aparelho de Estado (ABDO, C. H. N. et al., 2002; PAIVA, Vera et al. 2005). Porém, mesmo quando tratado, ele é relegado ao âmbito contingencial com exceção das ocasiões em que se refere diretamente à reprodução, ás taxa de natalidade, ao aborto, e às doenças sexualmente transmissíveis,

\footnotetext{
${ }^{1}$ Graduando em Filosofia pela Universidade de Brasília. Email: pedrofariasmentor@gmail.com. 
como fica evidente em campanhas preventivas em datas biopoliticamente estratégicas (LOYOLA, 2000).

Dentro do contexto acadêmico brasileiro atual percebemos certa presença do tema em disciplinas sob essas e outras perspectivas como demonstram Rizza, Ribeiro e Mota em um artigo publicado em 2016 sobre a presença de disciplinas que discutem a sexualidade nos currículos do Ensino Superior diagnosticaram que:

Das 38 universidades federais que ofertam disciplinas, essa oferta se dá em diferentes cursos de graduação [..] No entanto, é possível perceber que em alguns desses cursos a oferta de disciplinas é mais significativa. Dos 82 cursos acima listados nos quais encontramos disciplinas que tratam da sexualidade sendo ofertada, 39 deles oferecem mais de uma disciplina. Já nos 43 cursos restantes, encontramos apenas uma disciplina de sexualidade sendo ofertada” (RIZZA, RIBEIRO, MOTA, 2016, p. 208-209).

Sendo elas pertencentes aos cursos de:

Administração (2)2; Administração Pública (2); Agronomia (1); Arquivologia (1); Artes Cênicas Licenciatura (1); Artes Cênicas -Habilitação Teatro Licenciatura (1); Biotecnologia (1); Ciências e Tecnologia (1); Ciências Agrárias Licenciatura (1); Ciências Biológicas Bacharelado (2) e Licenciatura (9); Ciências Contábeis (1); Ciências da Computação Licenciatura (1); Ciências da Religião Bacharelado(1) e Licenciatura (2); Ciências Sociais Bacharelado (36) e Licenciatura (41); Ciências Sociais Habilitação Antropologia Bacharelado (3); Ciências Sociais - Habilitação Sociologia Bacharelado (3); Cinema e Audiovisuais (1); Comunicação Social - Habilitação em Jornalismo (3); Ciências Naturais (2); Comunicação Social - Habilitação em Publicidade e Propaganda (2); Comunicação Social Habilitação em Relações Públicas (2); Dança Bacharelado (1) e Licenciatura (2); Direito (6); Economia (1); Economia Doméstica Bacharelado (2); Educação do Campo Licenciatura (1); Educação do Campo - Habilitação em Linguagens Licenciatura (1); Educação Física Bacharelado (1) e Licenciatura (5);Educação Musical Licenciatura (2); Enfermagem (7); Engenharia Agrícola (1); Engenharia Civil (1); Engenharia de Alimentos (1); Engenharia de Aquicultura (1); Engenharia de Energia (1); Engenharia de Produção (1); Engenharia Mecânica (1); Estudo de Gênero e Diversidade (28); Física Licenciatura (4); Fonoaudiologia (1); Geografia Bacharelado (2) e Licenciatura (3); Gestão Ambiental (1); Gestão Pública (1); História Bacharelado (15) e Licenciatura (20); Humanidades (1); Intercultural Indígena Licenciatura (1); Interdisciplinar em Ciências Humanas (1); Interdisciplinar em Educação no Campo Licenciatura (1); Letras Língua Espanhola e suas Literaturas Bacharelado (1); Letras Língua Estrangeira Inglês e Espanhol Licenciatura (2); Letras Língua Estrangeira Moderna ou Clássica Licenciatura (2);Letras Língua Portuguesa (1); Letras Língua Portuguesa e suas Literaturas Bacharelado(1); Letras Português Inglês (1); Letras Português Literatura (1); Letras Vernáculos Licenciatura (1); Letras Vernáculos Língua Estrangeira Moderna Licenciatura (2);Matemática Licenciatura (4); Medicina (3); Museologia (2); Nutrição (1); Pedagogia 
Licenciatura (58); Políticas Públicas Bacharelado (2); Produção Políticas e Cultural Bacharelado (1); Psicologia Bacharelado (32) e Licenciatura (6); Química Bacharelado (1) e Licenciatura (2); Relações Internacionais (1); Saúde Coletiva (5); Serviço Social (12);Sistemas de Informação (1); Sociologia Bacharelado (3); Teatro Licenciatura (1); Terapia Ocupacional (2) e Zootecnia (1) (RIZZA, RIBEIRO, MOTA, 2016, p. 208-209).

Constatamos que há um vácuo em relação ao tema da sexualidade nas disciplinas da graduação em filosofia nas Universidades Federais! Com a emergência ainda mal-entendida dos estudos de gênero (Es. G.) tanto dentro quanto fora da academia - muitas vezes relegados a um recorte epistêmico mínimo e sujeito a generalizações grosseiras - temos uma oportunidade para (re)pensarmos de forma interseccional a radicalidade de certas categorias como capacitismo, nacionalidade, etnia, sexualidade e a classe (SILVA, 2017). Dentro de certa narrativa hegemônica dos estudos de gênero especialmente aquela feita e midiatizada pelo atlântico norte inglêsfrancês - e literalmente comprada pelo atlântico sul - há uma redução de parte dessas "camadas" de realidade a meros instrumentos complementares, entendidas enquanto ferramentas descartáveis (ARARUNA, 2017/2018; hooks, 2015). ${ }^{2}$ como se fossem "questões de escolha ou subjetividade intocável" e não eixos determinantes para a formação de mentalidades, das práticas culturais, ciências (metodologias, resultados e aplicações), meios de produção, divisão de trabalho, organizações sociais hegemônicas e/ou dissidentes (GONZALEZ, 1989; RODOVALHO, 2017; GABRIEL, 2011) como é o caso das "lascívias", os terceiros mundismos, as deficiências físicas, a interlocução com as culturas sobreviventes ou aniquiladas.

Tendo em vista esse reducionismo, o que esse artigo propõe é discutir uma filosofia da sexualidade que não apenas trate de reflexões extraídas de investigações científicas e ações políticas expressas sob o signo do identitarismo, mas uma pluralidade ora discordante, ora conciliatória de pensamentos que levem em conta de maneira consciente ou não, uma tradição filosófica a respeito da origem das experiências sensoriais e suas significações, das teorias do conhecimento, do expurgo gradual do corpo da própria realidade, das formas de vida (HADOT, 2014), das teorias políticas

\footnotetext{
${ }^{2}$ Se pegarmos como medidor os sites de compras de livros mais famosos no Brasil como Amazon, Livraria Cultura e Livraria Saraiva percebemos a presença massiva de autorxs estrangeiros nas abas de estudos de gênero, diversidade sexual e raça, enquanto as produções nacionais destacam sempre os mesmos livros e nomes.
} 
(FOUCAULT, 2013), das sistematizações éticas, da divisão entre a res pensante e res extensa nas ciências (DESCARTES, 2012) e assim por diante. ${ }^{34}$ Com ela entramos em um debate milenar atualizado à nossa linguagem de forma a pensarmos nossa contemporaneidade.

Falar da sexualidade nesse sentido também é radicalizar os problemas de gênero no que talvez seja o seu cerne - a identidade "subvertida" e subversiva, a representação almejada, os usos dos prazeres, a politização dos afetos - e consequentemente uma abertura para podermos trazer o mundo descolado da filosofia acadêmica ao universo do imprevisível que tanto a alimentou e ainda a alimenta. No Brasil, percebemos uma enorme carência de filosofxs na área que trabalham com esses assuntos explicitamente, por outro lado temos uma safra rica de pensadorxs na pedagogia, sociologia, antropologia e na psicanálise que por serem "áreas não-filosoficas" forneceriam materiais substanciais para um diálogo filosófico (DELEUZE, 1999). Por isso, o presente artigo pretende explicitar a necessidade e a possibilidade de falarmos de filosofias das sexualidades como um influxo importante na renovação dos cursos e dos debates em filosofia, principalmente em universidades mundialmente periféricas como são as universidades públicas do Brasil.

Para tanto, partiremos (I) das definições etimológicas e conceituais do termo "sexualidade", (II) a relação entre o espaço acadêmico, estudos de sexualidade, a atividade filosófica e o papel do senso comum, (III) um breve esboço da história da sexualidade no pensamento europeu, (IV) um interlúdio sobre as diferenças entre filosofia no, a partir e do Brasil para que possamos pensar as especificidades nacionais, e finalmente (V) uma introdução de alguns agentes brasileiros que contribuem incessantemente ao tema. Atentara-se para o fato que as reflexões filosóficas podem, devem e estão em diálogo com pesquisadorxs e linguagens pertencente a

\footnotetext{
${ }^{3}$ Sobre a objetividade da ciência MacKinnon diz: "Vou argumentar que a relação entre objetividade como postura a partir da qual o mundo é conhecido e o mundo que é apreendido dessa forma é a relação de objetificação. A objetividade é a postura epistemológica da qual a objetivação é o processo social, da qual a dominação masculina é a política, a prática social concretizada em ações.Isto é, olhar o mundo objetivamente é objetificá-lo. O ato de controle do qual aquilo que eu descrevi é o nível epistemológico é, em si, erotizado sob a supremacia masculina. Dizer que as mulheres são objetos sexuais é, desta forma, redundante. A objetivação sexualizada é o que define as mulheres como sexuais e como mulheres sob a supremacia masculina" (MIGUEL \& BIROLI, 2013, pp. 235 - 236)".

${ }^{4}$ Sobre o identitarismo, o embate das teorias de Nancy Fraser e Iris Young é importante para pensarmos as diferenças e/ou confluências entre reconhecimento e redistribuição.
} 
outros mundos - Sociologia, Pedagogia, Artes, Direito, Militância Organizada e Militância de Cotidiano.

\section{O QUE DIZEMOS QUANDO FALAMOS 'FILOSOFIA DA SEXUALIDADE’?}

Atividade necessariamente realizada por orientação ou preferência. Problema de interioridade subjetiva-individual ou circunstancialidade externa-social. Idoneidade dos sentimentos. Movimentação instintiva que pode se expressar, intensificar, mitigar ou emudecer. Qualidade de ser ou está... Partindo de uma leitura cruzada do principais dicionários da língua portuguesa e da língua inglesa o termo sexualidade teria todo esse conjunto de significados. ${ }^{5}$ Se tentarmos atravessar a polissemia da palavra lograríamos em observar múltiplas separações sob os signos de fixidez ou de fluidez, um mistério de devir ser e deveria ser, "manipulatividade" demarcativa de diferenças. ${ }^{6}$ E isso não é coincidência: 'sexualidade' possui um radical muito curioso. Sexus. A mesma que dá origem a palavra 'sexo'.

Segundo o English Etymology Or A Derivative Dictionary Of The English Language: In Two Alphabets (1783) de George William Lemon sexus é uma derivação do verbo seco - ato de dividir o animal entre macho ou fêmea, tendo uma conotação muito mais masculina na medida em que surge do sentido de virilidade fecundadora (seecus; virile; as muliebre sexus), relacionada a habitus, corporis conflitutio, sive animi. Já na The Encyclopaedia of sexual behaviour: volume two (1961) de Albert Ellis a palavra sexo aparece pela primeira vez na língua inglesa em 1382 na tradução da Bíblia de John Wycliffe, mas é apenas a partir de 1631 que terá a conotação moderna; com a exceção da origem latina para a divisão entre sexus virilis (distinção para homem) e sexus muliebris (disintação para mulher), a gêneses da palavra é indeterminada. Segundo o Wikitionary, sexus é também de origem incerta, comparada a seco (cortar) possui uma consoante similar a vehō (transportar, carregar), vēxō (mover, vibrar,

\footnotetext{
${ }^{5}$ Sendo eles as versões eletrônicas dos seguintes dicionários: Aurélio, Michaels, Cambridge e Oxford. Todos visitados no dia 22.02.2019 e com as referências completas na seção 'Bibliografia'.

${ }^{6}$ Uso a palavra manipulatividade como contraponto de manipulável. Enquanto na segunda temos uma noção de controle deliberado com fins parciais e em eterno movimento, a primeira portaria um tom pretensamente mais neutro, difícil de prever, porém ainda em acontecimento, próxima ao método de investigação científica que mesmo nos laboratórios supostamente recriaram as condições de uma natureza para depois redefini-la.
} 
desistir, causar estremecimento), flectō (curvar, enrolar, virar, suavizar) e flexum (do participativo flexus, dobrar, submeter, desviar, torcer).No Online Etymology Dictionary além das definições anteriores encontramos: sexus, "estado de ser masculino ou feminino, gênero"; associada a palavra seco enquanto divisão ou metade de uma raça, dividir ou cortar, citado da obra de De Vaan, o site aponta que:

\begin{abstract}
"Secus seems the more original formation, but it is strange that the older texts only know sexus. The modern meaning of sectiō 'division' suggests that sec/xus might derive from secāre 'to sever', but the morphologyI remains unclear: does sexus go back to an s-present *sek-s- 'to cut up', or was it derived from a form *sek-s- of the putative s-stem underlying secus?" (ONLINE ETYMOLOGY DICTIONARY apud DE VAAN, 2008).
\end{abstract}

Em outras palavras, a sexualidade tal como conhecemos, fazemos uso cotidiano e organizamos um entendimento talvez seja algo muito mais recente na história da humanidade (coisa iniciada entre os séculos XII - XVII para cá). Contrastando com a crença de que haveria desde o "início" uma binaridade irrefutável e contínua intuitivamente ou sistematicamente entre "homem/mulher" (cultural e fisiológica), fora da temporalidade que condicionam suas inteligentibilidade percebemos que teríamos de revisar e reescrever nosso entendimento de masculinidade e feminilidade anteriormente ao período renascentista atentando às descontinuidades das "essencialidades" sem esquecer as geografias orientais, africanas, americanas antes da colonização e os processos contemporâneos de subjetividade que participarmos ativa ou passivamente.

Nesse sentido, a consideração atribuída à Kierkegaard de que "sem pecado, nada de sexualidade, e sem sexualidade, nada de História" deveria passar por uma arqueologia de pelo menos três níveis: 1) Um entendimento do como a sexualidade se articula ou rompe com os tópicos de ontologia (especialmente no sentido de "para-alémda-física" e suas categorias de substância, acidentalidade e necessidade); ${ }^{7}$ 2) Uma investigação acerca da moralidade, das condutas éticas e práticas políticas que cercam as epistemologias do corpo e que são produzidas por essa última, 3) Uma dilatação do exercício indagativo que lide com o jogo de psiquismo e poder nos universos linguísticos, nas práticas habituais que extrapolam as abadias acadêmicas e nas relações

\footnotetext{
${ }^{7}$ Tal como Judith Butler aponta desde seu primeiro livro Problemas de Gênero até Corpos em aliança e A política de ruas. 
interpessoais científicas, filosóficas, artísticas e religiosas... Em suma, teríamos que entender qual noção sexualidade e qual história Kierkegaard está falando dentre as várias concebíveis. Não que o ato sexual, o gênero e as excitações do corpo não fossem tematizados antes das chamadas teorias queer, estudos feministas, estudos LGBT+ ou da psicanálise. De fato, encontramos em Safo, Platão, Agostinho, Christine de Pizan, Sor Juana Inês de La Cruz, Rousseau, Marquês de Sade, John Stuart Mill, Flora Tristan, Schopenhauer e muitxs outroxs considerações que se encaixam nos temas de sexo, gênero e sexualidade. Da mesma forma que certas experiências culturais não deixaram de existir com a falta de problematizações sistematizadas como por exemplo, a repressão dos apetites sexuais na idade média européia, as escolas de gênero na antiguidade grega e a pornografia desde Maria Antonieta - esquecer esse background seria negligenciar as "condições de possibilidade" históricas para que entre os primeiros séculos da modernidade a sexualidade "nasça" enquanto divisão que se dá em uma série de processos ora agenciados ora "viralizados" a saber: de corpos anatomizados e racializados, de técnicas e tecnologias que vão desde as alimentícias e vestuários passando pela a passabilidade, o sistema jurídico, as relações de trabalho desembocando nas drogas (lícitas ou ilícitas), cirurgias e meios semióticos. ${ }^{8}$ Afinal, uma palavra, um conceito ou um jargão quanto mais pertos estiverem historicamente e geograficamente do leitor mais experiências virtualmente ou atualmente portarão, no caso da sexualidade (seco, divisão) ela permeia ao menos enquanto linguagem o Ocidente há um bom tempo. ${ }^{9}$

Dessa forma, as sexualidades não seriam exclusivamente formas de sentir prazer (embora também o seja e desempenhe um papel relevantíssimo), mas uma série intencionalidade e cruzamento de usos dos corpos, de ocupação ou não de espaços reais e ficcionais - e os questionamentos dessa dicotomia -, de performances culturalmente parodiadas ou compulsórias, de redes de significações tanto nas experiências particulares quando nos regimes políticos que vinculam a religião, economia, as

\footnotetext{
${ }^{8}$ Sobre o uso político da pornografia com tática política de satirização à imagem de Mária Antônieta ver: Propaganda PORNOGRÁFICA contra Maria Antonieta. Leitura Obriga HISTÓRIA. Disponível em: <https://www.youtube.com/watch?v=QnsIiOMRh8Y>. Acesso: 21.02.2019.

${ }^{9}$ No sentido que Pierre Lévy utiliza: "Já o virtual não se opõe ao real, mas sim ao atual. Contrariamente ao possível, estático e já constituído, o virtual é como o complexo problemático, de tendências ou de forças que acompanha uma situação, um acontecimento, um objeto ou uma entidade qualquer, e que chama um processo de resolução: a atualidade.” (LÉVY, 1999, p. 16.)
}

Programas de Pós-Graduação em Ciências Sociais e Filosofia - UNIOESTE - Rua da Faculdade 645. Toledo - PR. CEP 85.903-000 Email: revistaalamedas@gmail.com 
linguagens e os gêneros (que se apresentam apoiados) e as movimentações de um para o outro, o questionamento do que é, quem e como se faz as epistemologias e as ciências, de criação e destruição de categorias universalistas e de compreensão, da separação entre analiticidade e experiência, das divisões ou não entre individualidades, das binaridades, das normas burocrática, de sentimentos e afetos, da história da metafísica da substância, da racialização, dos queers, dos crips, dos ciborgues e finalmente a articulação disso tudo com o próprio sentido de Humanidade. Assim como a proibição e desconsideração de tudo isso, porque a negação desse debate é de interesse dos estudos de sexualidade.

Em sínstese: a sexualidade é a expressão de uma divisão (das várias que podem existir) através de uma série de realidades que parte do corpo e todos seus associados ecoando desde as estruturas nanoparticulares até o que é mais "objetivo", "exterior, "factual" e "eterno". Sexualidade: controle, separação, territorialização... Partilha. ${ }^{10111213}$

\footnotetext{
${ }^{10}$ Segundo Foucault: "A escala, em primeiro lugar, do controle: não se trata de cuidar do corpo, em massa, grosso modo, como se fosse uma unidade indissociável mas de trabalhá-lo detalhadamente; de exercer sobre ele uma coerção sem folga, de mantê-lo ao nível mesmo da mecânica - movimentos, gestos atitude, rapidez: poder infinitesimal sobre o corpo ativo. O objeto, em seguida, do controle: não, ou não mais, os elementos significativos do comportamento ou a linguagem do corpo, mas a economia, a eficácia dos movimentos, sua organização interna; a coação se faz mais sobre as forças que sobre os sinais; a única cerimônia que realmente importa é a do exercício. A modalidade enfim: implica numa coerção ininterrupta, constante, que vela sobre os processos da atividade mais que sobre seu resultado e se exerce de acordo com uma codificação que esquadrinha ao máximo o tempo, o espaço, os movimentos. Esses métodos que permitem o controle minucioso das operações do corpo, que realizam a sujeição constante de suas forças e lhes impõem uma relação de docilidade-utilidade, são o que podemos chamar as "disciplinas". (FOUCAULT, 1987, p. 163 - 164)

${ }^{11}$ Sobre a separação sexual do trabalho, Federici diz: "Como demonstra essa breve história das mulheres e da acumulação primitiva, a construção de uma nova ordem patriarcal, que tornava as mulheres servas da força de trabalho masculina, foi de fundamental importância para o desenvolvimento do capitalismo. Sobre esta base, foi possível impor uma nova divisão sexual do trabalho, que diferenciou não somente as tarefas que as mulheres e os homens deveriam realizar, como também suas experiências, suas vidas, sua relação com o capital e com outros setores da classe trabalhadora. Deste modo, assim como a divisão internacional do trabalho, a divisão sexual foi, sobretudo, uma relação de poder, uma divisão dentro da força de trabalho, ao mesmo tempo que um imenso impulso à acumulação capitalista." (FEDERIC, 2017 p. 232)

${ }^{12}$ Àquela de Deleuze e Guattari: "Mas de modo algum é da mesma maneira e nem são as mesmas coisas, conforme as descodificações sejam retomadas ou não numa axiomática, conforme se fique nos grandes conjuntos que funcionam estatisticamente ou se atravesse a barreira que os separe de posições moleculares desligadas, conforme os fluxos de desejo atinjam este limite absoluto ou se contentam em deslocar um limite relativo imanente que se reconstitui mais adiante, conforme os processos [294] de desterritorialização se dupliquem ou não em reterritorializações que os controlam, conforme o dinheiro queime ou flameje." (DELEUZE \& GUATTARI, 2017, p. 327 - 328)

${ }^{13}$ No sentido de Jacques Rancière propõe: "Denomino partilha do sensîvel o sistema de evidências sensîveis que revela, ao mesmo tempo, a existência de um comum e dos recortes que nele definem lugares e partes respectivas. Uma partilha do sensîvel fixa portanto, ao mesmo tempo, um comum partilhado e 


\section{ACADEMIA, CURSOS DE FILOSOFIA E SENSO COMUM}

Sendo o senso não acadêmico de que as universidades públicas brasileiras estariam infestadas de pensamentos de vertente esquerdista na vivência percebemos um desfalque dentro das salas de aula de textos que ao menos toquem contingencialmente nos assuntos lidos como parasitas, especialmente os da sexualidade com recorte em orientação sexual e cis/transgeneridade embora a divisão de trabalho homem/mulher talvez apareça um pouco mais forte. A História da Sexualidade é imensa, riquíssima e ainda assim silenciada, ridicularizada e moralizada. E, por mais que os colegas estudiosos venham produzindo e debatendo de forma intensa sem a preocupação das linhas divisórias de ciências, linguagens e filosofia - integrando áreas - há ainda uma resistência considerável no ambiente acadêmico de aceitar o assunto com o devido respeito, principalmente no Brasil relegando, quando muito, à Foucault a cota de autorxs incontornáveis sobre micropolítica.

Enquanto na França e nos EUA grandes nomes estão abrindo portas para que esses preconceitos sejam vencidos, é de se perguntar até quando os grandes acadêmicos tupiniquins irão continuar na bolha, sem dar crédito ao trabalho coletivo de quem coordena e publica revistas e periódicos sobre o assunto, esperando os testes de laboratório estrangeiros para que "os corpos desviantes" estejam encarcerados e devidamente publicáveis:

\footnotetext{
"Afirmar que a filosofia brasileira vive em uma espécie de estufa cultural talvez não soe exatamente como uma novidade. Tal ambiente artificial tem sido elaborado desde o início da atividade filosófica entre nós e se fecha num círculo hermético, de tal forma que não são deixadas zonas de contato com o restante da cultura brasileira ou portas para o ambiente exterior. $\mathrm{O}$ cultivo da história da tradição filosófica, desenvolvida como objeto exclusivo de estudo nos cursos de formação no Brasil, consolidou essa situação. A estufa tem funcionado de acordo com seu propósito: é possível viver dentro desse isolamento cultural, estudar filosofia e exercer a profissão de filósofo durante anos, sem fazer referência a nenhuma situação nacional ou sem refletir sobre algo que seja específico do país. Assim, a filosofia brasileira não tematiza o país nem seus problemas. Ela tem uma vida que se reproduz ao longo do tempo, sem sair do seu castelo encantado." (SILVEIRA, 2016, p. 261).
}

partes exclusivas. Essa repartição das partes e dos lugares se funda numa partilha de espaças, tempos e tipos de atividade que determina propriamente a maneira como um comum se presta à participação e como uns e outras tomam parte nessa partilha." (RANCIÈRE, 2009, p. 15). 
Falando nos cursos de Filosofia a situação fica ainda mais grave. Como é o caso da Universidade de Brasília que mesmo sendo a primeira universidade do Brasil a ofertar a disciplina "filosofia e feminismo" vemos uma grande resistência em responder a fossilização do curso. Há um processo de museologização em andamento em que a filosofia está se tornando em um departamento de Estudos do Pensamento Branco Europeu-americano Masculino Heterossexual, negando-se a expandir suas fronteiras geográficas, físicas, nacionais, raciais e sexuais se pegarmos as ementas apresentadas em todos os semestres há algumas décadas.

Se a atividade chamada filosófica sempre está próxima dos momentos e dos assuntos que causam surdez no senso comum e cegueira no científico então ela não teria medo ir no cerne de tudo aquilo que é considerado em um primeiro momento como confuso e necessário (re)agir. Por isso, além de realizar autocrítica a si no sentido institucional também diagnostica a (in)consciência daquelx que pensa ou sente. Ela estaria sempre nos "entre", buscando incansavelmente. Ela ficaria no portão sem poder adentrar, atenta a tudo sem discriminar, sumariamente aquilo que é visto como novo. $\mathrm{X}$ sujeitx que se arroga a se aventurar na sujeira que é a Filosofia não deveriam ignorar o menor, o efêmero, "o muito pessoal para se falar", o mais degradante, o inquestionável, o que é mais desqualificado... algo tão delicado como a sexualidade, por exemplo. Porque é na ruminação e na inquietação que os meios, as separações pode ser com ou sem fins, para usarmos uma expressão agambeniana.

\section{PODEMOS ENTENDER A SEXUALIDADE COMO TEMA FILOSÓFICO?}

Assim como o gênero, a raça, as deficiências, os direitos (e daí terrorismo, (ini)mi( $(\theta)$ grantes e nacionalismo) a sexualidade é um termo repleto de páthos sociais. É abundante a emissão de comunicações sobre os direitos de casamento de pessoas cisgêneras homoafetivas, a relação das travestis com a prostituição ou as ocupações dos espaços privados pelos sem terra enquanto a discutir as possíveis relações entre a teoria das cordas e os multiversos ou como a relatividade de Einstein revoluciona a Física são 
relegadas para interessados específicos e especialistas. ${ }^{14}$ Mas por que? Creio que a resposta para isso não é simples e de forma alguma pode ser dada resumidamente em uma fala apressada, merecendo um estudo muito maior do que o pretendido aqui, por isso, tentemos considerar o desenvolvimento das ciências exatas e o esvaziamento dos conteúdos temporais - leia-se: tudo o que é perecível, "relativos" ou não passível de certeza intelectual estável- como responsáveis pela banalização, dessacralização e privatização de determinados temas em favor de outros bem como a massificação exponencial de certos assunto obedecendo ao regime senso comum na era pósguerra. ${ }^{151617}$ Como ambas balizas são muito mais extensa que o espaço permite passemos por elas de forma panorâmica.

\section{SEXUALIDADE, CIÊNCIA E MODERNIDADE}

A modernidade do pensamento - século XIV - XVIII - se consolida pelo ostensivo exorcismo do corpo da maquinaria do conhecimento e da metafísica européia por um adestramento e manuseio característico da sociedade emergente de tudo aquilo considerado abjeto, exótico, estrangeiro, selvagem e objetificável, principalmente na medicina (ver: B, M. R., Matos, P. M. \& Costa, M. E., 2011, pp. 24-34; LOYOLA, 2003, pp. 875-899). Mais a frente, essa mentalidade e os fenômenos associados serão materializados pela colonização dos povos da América, da África, parte do Oriente e posteriormente da Oceania, além da emergência dos estados nacionais, a transição da sociedade feudal para a sociedade capitalista, a guinada dos estudos cada vez mais

\footnotetext{
${ }^{14}$ NNum primeiro sentido, a comunicação é a transmissão e a propagação de uma informação. Ora, o que é uma informação? Não é nada complicado, todos o sabem: uma informação é um conjunto de palavras de ordem. Quando nos informam, nos dizem o que julgam que devemos crer. Em outros termos, informar é fazer circular uma palavra de ordem. As declarações da polícia são chamadas, a justo título, comunicados. Elas nos comunicam informações, nos dizem aquilo que julgam que somos capazes ou devemos ou temos a obrigação de crer. Ou nem mesmo crer, mas fazer como se acreditássemos. Não nos pedem para crer, mas para nos comportar como se crêssemos. Isso é informação, isso é comunicação; à parte essas palavras de ordem e sua transmissão, não existe comunicação. O que equivale a dizer que a informação é exatamente o sistema do controle. Isso é evidente, e nos toca de perto hoje em dia." (DELEUZE, 1999, pp. 10 - 11).

${ }^{15}$ Banalizar no sentido de que todos podem falar e ter certeza baseada na experiência individual.

${ }^{16}$ Dessacralizar na medida em que não são dignas de respeito sem passar pela descrença ou pelo escárnio.

${ }^{17}$ Privatizados porque embora todos possam falar de forma redutiva e galhofeira esses temas não podem pertencer ao fórum público permanentemente, nem tratados com seriedade ou de maneira significativa sem causar um desconforto sistemático do ordenamento do mundo dado que as experiências desses âmbitos "são sempre" de ordem privada e "apenas" escapolem vez ou outra. Logo, seriam relegados para dentro do arcabouço que se instala de forma comunal para depois se considerar invisível e natural.
} 
particulares em ambiente institucional, a reformulação dos espaços e da função das produções universitárias, a emergência das disciplinas militares, as viagens de expedições, a Literatura Comparada, os gabinetes de curiosidades, a etnografia, a frenologia etc. Sueli Carneiro retomando Boaventura de Sousa cita:

\begin{abstract}
O genocídio que pontuou tantas vezes a expansão européia foi também um epistemicídio: eliminaram-se povos estranhos porque tinham formas de conhecimento estranho e eliminaram-se formas de conhecimento estranho porque eram sustentadas por práticas sociais e povos estranhos. Mas o epistemicídio foi muito mais vasto que o genocídio porque ocorreu sempre que se pretendeu subalternizar, subordinar, marginalizar, ou ilegalizar práticas e grupos sociais que podiam ameaçar a expansão capitalista ou, durante boa parte do nosso século, a expansão comunista (neste domínio tão moderno quanto a capitalista); e também porque ocorreu tanto no espaço periférico, extra-europeu e extra-norte-americano do sistema mundial, como no espaço central europeu e norte-americano, contra os trabalhadores, os índios, os negros, as mulheres e as minorias em geral (étnicas, religiosas, sexuais) (CARNEIRO, 2005, p. 96 apud SANTOS, 1995, p. 328).
\end{abstract}

Com o positivismo a ciência se torna princípio meio e fim do Espírito Humano.

Todas devem corresponder ao progresso e aos ditames das leis universais. A figura de Comte é incontornável: é com perfazimento dos três estágios da história (teológico, metafísico e positivo) culminando na religião da humanidade que as epistemologias e o senso comum reproduzem o ideal de industrialização, avanço em pesquisas tecnológicas. No caso do Brasil o positivismo esteve ligado ao militarismo, aos liberais econômicos, aos republicanos e a valorização de uma tecnocracia (elementos que de forma alguma devem ser perscrutados de forma indissociável seja no sentido de reconstrução histórica, seja na articulação ideológica ou seja nos resultados esperados e produzidos):

Percebemos que existe uma ideia de que a educação é um espaço que pode fomentar o desenvolvimento, este entendido como progresso econômico e social. Não há como ignorar que haja resquícios do pensamento positivista que continuam a influenciar o pensamento educacional brasileiro. A concepção de educação escolar tecnicista acredita que fundamentalmente em soluções progressivas para os problemas econômico-sociais. Percebemos que a Filosofia Positivista deixou também resquícios na organização curricular da escola fundamentando uma ideia de que as "ciências exatas" possuem maior importância para o desenvolvimento tecnológico/industrial. Observando o panorama do mundo globalizado e suas influências econômicas no contexto brasileiro, compreendemos que as ideias Positivistas estão fortemente arraigadas em concepções de ensino que acreditam que exclusivamente a 
formação acadêmica científica e o ensino médio técnico podem fomentar o desenvolvimento do país (KRUL \& EMMEL, 2016, p. 10).

As produções epistêmicas desse quadro ecoam fortemente tanto no senso comum quanto no olhar cético dxs epistemologxs brasilerixs. Parte disso se deve a todo uma estrutura de conhecimento onde a mente e os órgãos da cabeça estão hierarquicamente acima do restante do corpo como local epistemologicamente privilegiado, especialmente em relação às mãos, os pés e as genitálias por conta da sua capacidade de arbitrariamente universalizar e abstrair tudo o que "percebe" sem a carne que habita. ${ }^{1819} \mathrm{E}$ isso não é uma metáfora! No continente europeu por mais de 2500 anos - e dai nos continentes colonizados - a alma que inicialmente fora portadora das mais variadas funções mantenedoras da vitalidade, como são os casos de Platão e Aristóteles (pensamento, sentimento, vontade, instinto e substrato que anima a vida) será gradualmente reduzida à mente como um centro detentor da capacidade de articulações lógicas e emissão linguística no período da Escolástica com Tomás de Aquino em que a alma terá três formas - mineral, animal e humana, sendo essa última caracterizada pela intelectividade.

Em Descartes, Berkeley, Kant e no movimento anatomista moderno é patente que o corpo não passa de um autômato, um relógio que a alma dá cordas. No caso do primeiro filósofo isso ocorre pela radicalização da diferença entre res cogitans (a coisa pensante, infinita, perfeita) e res extensa (a matéria, finita, corruptível), ou seja, bifurcação da natureza tal como Whitehead aponta. Em Berkeley ficamos a beira do solipsismo se não houvesse a figura divina para impedir que o mundo externo a mente não passasse de concepções da consciência atenta. Para Derrida, por exemplo, a

\footnotetext{
${ }^{18}$ Uso propositalmente entre aspas a palavra perceber para indicar a ligação linguística que há entre a experiência sempre é proveniente de algo em processo/contínuo, no sentido de Whitehead) e o conhecimento abstrato de forma que estranhe essa possibilidade real de separarmos em duas categorias os meios e o conteúdo do pensamento e o pensamento em si/formal.

19“'A princípio o tema do cu pode parecer esdrúxulo e espantoso, pois poderíamos vê-lo sem nenhuma dignidade filosófica, já que se costuma ponderar filosoficamente de forma mais contundente sobre a alma, sobre o etéreo, sobre o espírito etc., e deixa-se de lado toda a complexidade da corporeidade e seus elementos, do prazer com o corpo até a estranheza e desconforto com ele. Além disso, em regra, quando pensamos o corpo damos privilégio epistemológico para algumas partes e não para outras, sempre um maior valor para a cabeça e uma desvalorização do baixo-ventre. Dessa forma, compreendemos que há toda uma arquitetura política do corpo, as partes dignas e as partes indignas, as partes desejáveis e as indesejáveis.” (LEOPOLDO, 2015, disponível em: https://medium.com/@ralasfer/pelo-cupol\%C3\%ADticas-anais-por-uma-\%C3\%A9tica-da-passividade-884fb5cf8140. Acesso em: 22 de ago 2019).
}

Programas de Pós-Graduação em Ciências Sociais e Filosofia - UNIOESTE - Rua da Faculdade 645. Toledo - PR. CEP 85.903-000 Email: revistaalamedas@gmail.com 
filosofia estaria obrigatoriamente "timpanando" as coisas em sua própria linguagem que desde de sempre é logocêntrica. ${ }^{20}$ A consolidação das ciências exatas vai de encontro com o "objetividade" não apenas gerada discursivamente mas também naturalizada e reatroalimentada entre a Revolução Científica e a Revolução Industrial, que, diferente do logocentrismo anterior, se apóia de maneira tentacular nas novas normas jurídicas que perfazem o caminho das constituições até a fiscalização de cumprimento, as produções de conhecimento cada vez mais especializadas e o mercado que surge e se desenvolve vorazmente procurando, propagandeando e criando em alguns casos demandas. Aqui temos uma tradição consistente em que a divisão entre o que é calculável e consequentemente objetivo de um lado e toda realidade que não pode ser matematizável, comercializada ou identificada de outro deve ser capaz está subordinada a uma lógica implacável de estabilidade e capacidade reprodutiva de ipseidade. As ciências biológicas serão nos séculos XX e XXI o campo limite e convergente de todas esses problemas: clonagem, reprodução in vitro, mudanças genéticas, eutanásia, epidemias, bioterrorismo e etc - pois é por ela que esse choque se tornar algo de urgência óbvia (KOTTOW, 2003, pp. 297-303).

Enfim, percebemos que as divisões do corpo intra (a própria corporalidade e suas micropartes) e o extra (em direção daquilo que não pode ser o corpo) é desde de sempre uma paradoxalidade. Porque é de uma concepção do que é corpo, das suas funções e dos seus limites - muito mais que potencialidade - que se hierarquiza as outras divisões. Dentro das divisões há reverberações da sua semelhança. $\mathrm{O}$ mundo é habitado por imagens e, enquanto mundo humano, perpetuamente se faz um mundo imagético. Relegado à condição de acidente o corpo seria a própria imagem da divisão, do múltiplo, do rebelde, daquilo que tira certeza do pensamento. Foucault em um dos seus textos mais poéticos aponta que todas as utopias partem do corpo divagando pelos recantos da alma em uma longa caminhada para voltá-lo e regulá-lo:

\footnotetext{
20“'Para Derrida há um timpanizar da filosofia que é uma escuta que sempre se faz por meio de um mesmo limite, de um mesmo enquadre, que é justamente o que se deve romper, já que ele conforma e encerra todo o pensamento numa mesma rede conhecida, familiar. O tímpano se coloca como um filtro que transforma tudo no mesmo, que arrefece os golpes, que eqüaliza, tornando capturável pelos ouvidos tudo que os atinge. Numa palavra, a relação da filosofia com seu outro transforma todo outro em algo passível de ser apropriado, incluído." (CONTINENTINO, 2006, p. 22).
} 
Porém, a mais obstinada talvez, a mais possante dessas utopias pelas quais apagamos a triste topologia do corpo,nos é fornecida, desde os confins da história ocidental, pelo grande mito da alma. A alma funciona no meu corpo de maneira maravilhosa. Nele se aloja, certamente, mas sabe bem dele escapar: escapar para ver as coisas através das janelas dos meus olhos, escapa para sonhar quando durmo, para sobreviver quando morro. Minha alma é bela, é pura, é branca; e, se meu corpo lamacento - de todo modo não muito limpo - vier a sujá-la, haverá sempre uma virtude, haverá uma potência, haverá mil gestos sagrados que a restabelecerão na sua pureza primeira. Minha alma durará muito tempo e mais que muito tempo, quando meu corpo vier a apodrecer. Viva minha alma! É meu corpo luminoso, purificado, virtuoso, ágil, móvel, tépido, viçoso; é meu corpo liso, castrado, arredondado como uma bolha de sabão.

[...]

Meu corpo está, de fato, sempre em outro lugar, ligado a todos os outros lugares do mundo é, na verdade, está em outro lugar que não o mundo. Pois, é em torno dele que as coisas estão dispostas, é em relação a ele - e em relação a ele como em relação a um soberano - que há um acima, um abaixo, uma direita, uma esquerda, um diante, um atrás, um próximo, um longínquo. O corpo é o ponto zero do mundo, lá onde os caminhos e os espaços se cruzam, o corpo está em parte alguma: ele está no coração do mundo, este pequeno fulcro utópico, a partir do qual eu sonho, falo, avanço, imagino, percebo as coisas em seu lugar e também as nego pelo poder indefinido das utopias que imagino. Meu corpo é como a Cidade do Sol, não tem lugar, mas é dele que saem e se irradiam todos os lugares possíveis, reais ou utópicos (FOUCAULT, 2013. p. 9 e p.14);

Vemos que a sexualidade nunca esteve fora dos cálculos do poder, o que não implica seu reconhecimento. Da mesma forma que a divisão bem delineada entre o que é público e o que é privado sempre foi borrado pelas transgressões, imprevisibilidades, corrupções, invisibilidade ou não consciência plena dos espaços. O que nos leva a próxima questão: a massificação e reprodução de um senso comum sobre determinados tópicos.

\section{O PAPEL DO SENSO COMUM}

A sexualidade, como salientamos, estaria em uma área cinzenta onde a sua paradoxalidade entre o público e o privado é uma divisão entre aquilo que deve ser permitido e aquilo que deve ser proibido, mas sobretudo aquilo se fala constantemente para cobrir o enorme ruído que perpassa sua discursividade. Como se estivesse em tal relatividade que analiticamente jamais poderia ser localizada e determinada. Os entre espaços são ricos em conteúdos. Tal como uma árvore repleta de fungos microscópicos capazes de penetrar pelo contato em qualquer coisa, sobrevivendo da nutrição 
simbiótica e, dependendo do hospedeiro/parceiro, podendo ser meio de conservação de vida.

Ao contrário das efervescências políticas e das amarras ideológicas, o senso comum possui uma importância crucial. Não vivemos sem ele, porém sobre o nosso assunto faltam a consciência das raízes da sexualidade Como dissemos anteriormente, a sexualidade é uma divisão que em parte se direciona/parte ao/do corpo, mas:

Se, obviamente, a sexualidade envolve o corpo, não se restringe a ele nem é uma simples derivação do seu funcionamento. Boa parte da experiência da sexualidade se dá através do corpo, mas também a partir de outros lugares e práticas, e de como essas práticas definem a nossa relação com o corpo.A sexualidade está na lei, na regulação das relações conjugais, dos modelos de família, das práticas sexuais que são permitidas ou proibidas. Está também nas políticas de natalidade, nos cartórios de registro civil, na proibição ao aborto e na polêmica sobre educação sexual nas escolas.A sexualidade está na ciência, que se dedica a investigar suas origens, que define as etapas do seu "desenvolvimento", que cria categorias para explicar suas várias expressões e, a partir daí, definir o que é normal ou anormal, precoce ou tardio, saudável ou patológico. Várias palavras e conceitos que usamos para pensar e falar sobre sexualidade derivam do pensamento científico. É possível dizer, com pouca margem de dúvida, que hoje a ciência - especialmente a biologia e a psicologia - é o discurso mais acionado (que mais gente usa) e mais legitimado (que mais gente reconhece como válido) para falar da sexualidade.A sexualidade está na religião, nos seus mitos de origem, nas regras que estabelecem, nos comportamentos que induzem, definindo o limite do moral e do imoral, do pecado e da virtude, do "natural" e do ""antinatural" segundo alguma doutrina. E, mesmo que você não professe qualquer religião, seu modo de pensar sobre o sexo, o amor, a família, o casamento, certamente é influenciado, em alguma medida, pelo pensamento religioso.A sexualidade está nos meios de comunicação, na produção cultural que acessamos todos os dias, nos corpos "perfeitos" que se exibem na TV, nos casamentos de novela, na polêmica do "beijo gay", na erotização de crianças, na construção de modelos estéticos que definem o que é bonito e o que é feio, o que é desejável ou repulsivo, o que pode ser visto e o que precisa ser censurado.A sexualidade está no "mercado", empacotada para vender, da indústria pornográfica à família "modelo" do comercial de margarina. Está na indústria farmacêutica, do anticoncepcional ao viagra, dos remédios para perder peso aos que aumentam a massa muscular. Está nas campanhas "ousadas" que transformam a transgressão sexual em estratégia de marketing, na imagem anoréxica das capas de revista e na publicidade infantil. Está nos processos seletivos do pessoal dos recursos humanos, definindo quem entra e quem ascende (ou não) no mercado de trabalho.Assim, embora o corpo seja o território privilegiado da sexualidade, ela não se resume a um aspecto do seu funcionamento, nem é uma expressão "natural" da sua fisiologia. Mais que isso, a sexualidade é uma das formas pelas quais trazemos o corpo para a cultura. Inserimos o corpo nas relações de poder, tornamos o corpo pensável e compreensível por meio da linguagem, formamos esse corpo nos discursos e nas práticas sociais.A sexualidade não é um dado da natureza que a ciência tenta desvendar, um impulso interior que a religião tenta conter ou que a lei aparece para regular. A sexualidade, tal qual nós a vivemos, é justamente o produto de todas essas práticas e discursos científicos, religiosos, legais, morais, estéticos, entre tantos outros. Práticas e 


\begin{abstract}
discursos que, mais do que descobrir, proibir ou controlar, vão efetivamente produzindo a nossa sexualidade. A sexualidade é uma produção social e, como tal, é construída de formas distintas em diferentes sociedades e momentos históricos. Portanto, o que percebemos, entendemos e experienciamos como sexualidade tem a ver com o corpo e como construímos esse corpo na cultura e nas relações em que estamos inseridos, no tempo histórico em que vivemos.

Se a sexualidade é um produto histórico, construído socialmente, isso significa que a forma como a compreendemos e experienciamos se transforma de cultura para cultura e ao longo do tempo. A sexualidade já recebeu muitos nomes, já foi vivida de muitas maneiras ao passar dos séculos, de forma que é possível pensarmos mesmo em uma "história da sexualidade". Uma história de como cada sociedade, ao longo do tempo, foi construindo e reconstruindo formas de viver e pensar a sexualidade. Um movimento de conservação e subversão em que o tradicional e o novo se encontram, recorrentemente se confrontam e vão, sucessivamente, dando novas formas a isso a que chamamos sexualidade. Isso significa que a forma como vivemos hoje o afeto, as relações, o prazer e o corpo não é a única, nem a primeira, nem a última. E o que parece constante e imutável pode estar se transformando radicalmente nesse exato momento." (DO CURSO PROMOÇÃO E DEFESA DOS DIREITOS LGBT COMO PARTE DO PROGRAMA NACIONAL DE EDUCAÇÃO CONTINUADA EM DIREITOS HUMANOS (PNEC_DH) ORGANIZADA PELA ENAP).
\end{abstract}

Por isso é interessante notar como essas discussões são colocadas por perspectivas deslocadas e deslocáveis. A localização da sexualidade como categoria filosófica no Brasil assume uma tônica muito diferente dos paradigmas franceses ou estadunidenses.

Vários Brasis também compõe nossa casa, há lugares de fala que vão da linha de fogo dentro da floresta amazônica até as pequenas fazendas no interior sulista, do pantanal do centro oeste até as danças do bumba meu boi no nordeste.

\title{
LIMIAR: FILOSOFIA NO, A PARTIR E DO BRASIL
}

Palavras importam e para o maior rigor filosófico devemos fazer diferenciações entre Filosofia no Brasil, Filosofia a partir do Brasil e Filosofia do Brasil.

Aqui interpretamos Filosofia no Brasil como a "aplicação" da Filosofia Estrangeira ao cenário brasileiro. Nesse sentido, há dois pontos interessantes a serem ressaltados: o estrangeiro pode ser aquilo que constitui a identidade nacional enquanto oposição ou que será aprisionado para definir a comunidade e o monstro que desestabiliza a normalidade por sua ação zigue zague. Logo, o estrangeirismo surge de um lado como a colonização do pensamento e do outro as tradições sincretizadas. A 
Filosofia no Brasil é uma passagem da "amizade pelo conhecimento" de forma imperial, mas que não s deixa de abrasileirar-se. Essa Filosofia é dependente constante das mudanças no continente europeu da noção do que é ou o que não é o fazer filosófico uma vez que essa é um projeto teleológico que jamais perde a vontade de sua irradiação.

Filosofia do Brasil é uma visão generalizada que ao contrário da anterior se mantém ligada ao nacionalismo implícito. Acima de tudo, a Fil. do Brasil persegue uma unicidade e cosmopolitismo e devido a isso está ligada às questões das modalidades historiográficas bem restritas ou que tendem a se estratificar facilmente. Talvez seja aquela mais ligada aos projetos políticos do modernismo e do positivismo.

Filosofia a partir do Brasil é mais delicada. Delicada porque vemos o Brasil como processo e solidificação, mas não eternização, logo, mais fácil de sempre estarmos voltando as origens e as derivadas numa leitura que espero que seja mais crítica, que entenda as divergências que solapam ou que edificação pensamentos, sistemas ou que (aparentemente) os impossibilitam. A partir do Brasil é um ponto de início que já toma o princípio como algo em movimento e que tenta chegar no geral sabendo que sua desconstrução também é construção porque se dá entre o rastro. Por isso a Filosofia da Sexualidade, ou melhor, as filosofias das sexualidades no Brasil seria mais frutífera caso partissem das partilhas e não das teleologias.

Filosofias das sexualidades a partir dos brasis.

\section{FILOSOFIA DA SEXUALIDADE A PARTIR DO BRASIL: UMA FORMA DE RENOVAÇÃO PELO DIÁLOGO DE CONHECIMENTOS-EXPRESSÕES}

As identidades sexualizadas a partir dos brasis são maiores que as políticas de reconhecimento. São multidões que subjetivadas e sujeitas além da heteroxetualidade e da "limpinha" comunidade LGBT, são HsH, MsM, baitolas, travecos, sapatões, gays, hermafroditas, agêneros, drag queens, drag kings, pocs e etc. É todo o caldo cultural que existe efetivamente e não como ideal, um plano - são experiências entremeadas que partem de nossas próprias questões e primazias nacionais, grupais e individuais. Partir dessas sexualidades, sexualizações, identidades, contra-sexualidade, contrasexualizações, a-identidades e contra-identidades não são apenas recortes de vivência ou criatividade de afetos e sim consciência de experiências e tradições organizações e 
organizadoras da realidade política, epistemologia, ontologia ética, estética e antropológica.

De fato, temos uma grande quantidade de tomos de filosofia, pesquisas etnográficas, reconstituição documental realizada com zelo e dedicação antes mesmo das primeiras universidades. A característica mais marcante das pesquisas sobre sexualidade nos brasis é o seu formato de divulgação e seu contexto universitário já instaurado: os artigos científicos e ensaios - escrever sobre sexualidade partindo disso poderia ser encarado como uma discussão muito mais ampla no que concerne a autoria, afinal, nos volumes e números dos periódicos uma quantidade maior de pessoas se reúne para ler, divulgar e escrever.

Não quero dizer que os livros de autores reduzidos ou coletâneas não existiam, muito menos que perderam seu valor, mas que as revistas e periódicos são mais dinâmicas, acessíveis e experimentais (justamente por não cederem às altas exigências das editoras - o que não quer dizer que não há burocracia de formatos e regras de ABNT nas publicações semestrais e anuais, sem esquecer os níveis de hierarquias que privilegiam ou tornam exclusivas os manuscritos de mestrandos e doutorandos). Nelas vemos os mais diversos modelos metodológicos - quantitativos, qualitativos, poéticos, biográficos, autobiográficos, teatrais, contistas, entrevistas e etc.

Ou seja, nem todas as publicações são de pessoas formadas em filosofia ou que sequer considerem sua escrita como filosóficas. O que significa para alguns, os graduandos em Filosofia, um afastamento automático para as torres de marfim dos entendedores de jargões em alemão ou grego antigo, assim como uma estereotipização da atividade filosófica como aquela "ciência humana" que estuda Platão, Aristóteles e Kant já ultrapassada/anedota histórica nada rebelde da criação do conhecimento. Porém, parte da renovação das mentalidades acadêmicas é ler, estudar e principalmente debater com professores, estudantes e colegas os textos, autorxs e meios. E é por isso que é importante ressaltar que os periódicos sobre sexualidade são em grande parte constituídos por pessoas que realizam essa alquimia de saberes.

\section{NOMES}


A Periodicus é o resultado de um esforço do CUS - grupo de pesquisa de cultura e sexualidade vinculado a Universidade Federal da Bahia (UFBA). Desde de 2014 vem se consolidando como uma das maiores fontes de estudos internacionais e agenciadores. Já trouxe nos seus dossiês temas como: Corpo, política, psicologia e psicanálise: a produção de saber nas construções transidentitárias (2016), Crianças desviadas, sexualidades monstruosas, educação pervertida: paisagens alteritárias das infâncias (2018), Cartografia dos estudos queer na Ibero-América (2014) e Sapatão é revolução! Existências e resistências das lesbianidades nas encruzilhadas subalternas (2017).

A Revista de Estudos Feministas vinculada à USFC pública desde 1992 vem com a incrível frequência de três volumes por ano de contribuintes nacionalmente interessados e internacionalmente requisitados, os dossiês já cotejaram: os balanços da lei Maria da Penha, Gênero, Cinema e Audiovisual, Ecofeminismo, Psicanálise e Gênero, Transfeminismo e etc.

Vinculada a UFPB, a Revista Ártemis segue a mesma linha interdisciplinar: desde 2004, bem como a Bagoas do Centro de Ciências Humanas, Letras e Artes da Universidade Federal do Rio Grande do Norte, a Revista de Gênero, Sexualidade e Direito.

E entre outros poderíamos listar os Cadernos Pagu, revista labrys (UnB), Revista Diversidade e Educação (UFRG) e Das Questões (UnB).

Alguns nomes se destacam mais facilmente, mesmo subindo em ombros de gigantes.

Berenice Bento é professora na Universidade de Brasília, foi a primeira a levar as questões de transexualidade a sociologia brasileira. Escreveu $O$ que é transexualidade?, A reinvenção do corpo: sexualidade e gênero na experiência transexual e Transviad@s: gênero, sexualidade e direitos humanos.

Guacira Lopes Louro é referência internacional na área da Pedagogia, especialmente na postura do professor no desenvolvimento psico-sexual dos alunos. Entre sua vasta obra se destacam: Um corpo estranho: Ensaios sobre sexualidade $e$ teoria queer, Gênero, sexualidade e educação. Uma perspectiva pós-estruturalista e $O$ corpo educado. Pedagogias da Sexualidade. 
Richard Miskolci ficou conhecido pelo livro Teoria Queer: um aprendizado pelas diferenças, que já se tornou obra balizar no Brasil nos estudos culturais. Além disso publicou algumas obras e artigos sobre literatura, tecnologia e relacionamentos e a polêmica sobre a "ideologia de gênero".

João Silvério Trevisan, um ícone tanto por sua militância desde a época da Ditadura quanto pelo seu trabalho jornalístico, histórico, cinematográfico e prosa. Seu Devassos no paraíso - A homossexualidade no Brasil, da colônia à atualidade é a maior obra sobre a formação abrasileirada das identidades LGBT.

Os nomes poderia se extender numa longa lista, mas deixamos a ideia tal como diria a filósofa Ana Miriam Wuensch: onde há um, há muitos outros.

\section{CONSIDERAÇÕES FINAIS}

Pode a sexualidade ser filosófica, a filosofia ser sexual, a sexualidade da filosofia ou filosofia da sexualidade? A filosofia da sexualidade traria um desafio que em princípio é constante durante boa parte da história da filosofia ocidental (e quem sabe das africanas, orientais, latinas, indígenas e oceânicas também?): a tentativa de explicar e ou relacionar uma visão de mundo, uma forma de vida e um busca de sabedoria partindo daquilo que lhe é mais caro: o maravilhoso. Ora, dada algumas das indicações apresentadas até o momento podemos dizer que as quatro são possíveis.

A sexualidade é filosófica na medida que se move, não cessa de se expressar e passar por mutações sem jamais se acomodar embora possa e seja tragada, eivada ou contamine aspectos múltiplos da vida. A Filosofia é sexual quando divide ou questiona as divisões das realidades, quando lida ou deixa de lidar com o corpo, quando silencia vozes a favor de outra ou quando se apropria ou é apropriada pelxs negligenciadxs e desprezadxs. A sexualidade de Filosofia são sustentações invisíveis que resvalam as tradições de pensamento em suas marcações e irrefutabilidades mais lógicas e morais, são os espaços das asserções sacrosantificadas. A Filosofia da sexualidade é o rastreio impossível de concluir, é a atividade daquilo que resta do pensar, é a encruzilhada em que as multiplicidades singram sob e sobre a unicidade, a ordem, a razão, a linguagem e o invisível; ela é um meio de tentarmos comunicar aquilo que está além da sua própria condição de possibilidade ao mesmo tempo que o retorna (antrofalologocentrismo); é 
criação, é ambiguidade sem medo de assim o ser, é extensa como as pernas das aranhas, é coerente quando entra em contradição, é esquiza. A conclusão - em resposta ao nosso título - é simples: há sim Filosofia(s) da(s) Sexualidade(s) a partir do(s) Brasil(is) ainda em construção e anarqueologia feita em conjuntos escritos ou com os fantasmas que seguram nossa pena.

\section{BIBLIOGRAFIAS}

ABDO, Carmita Helena Najjar et al. Perfil sexual da população brasileira: resultados do Estudo do Comportamento Sexual (ECOS) do brasileiro. Revista Brasileira de Medicina, Brasília, v.59, p. 250-257, 2002.

ARARUNA, Maria Leo Fontes. $O$ direito à cidade em uma perspectiva travesti: uma breve autoetnografia sobre socialização transfeminina em espaços urbanos (Universidade de Brasília). Revista Periódicus, Bahia, v.1, n.8, p. 133-153, nov-abr, 2017/2018.

BARBOSA, Maria Raquel; MATOS, Paula M ena; COSTA, Maria Emília. Um olhar sobre o corpo: o corpo ontem e hoje. Psicol. Soc., Florianópolis , v. 23, n. 1, pp. 2434, Apr. 2011.

DESCARTES, René. Meditações Metafísicas. Trad.: Maria Ermantina de Almeida Prado Galvão. São Paulo: Folha de S. Paulo, (Coleção Folha. Grandes nomes do pensamento; v.5), 2015.

DELEUZE, Gilles. "O que é ato de criação" in: Duarte, Rodrigo. O Belo Autônomo: textos clássicos de estética. 2 ed - Belo Horizonte: Editora Autêntica; Crisálida, (Filôestética), 2015.

DELEUZE, Gilles \& GUATARRI, Félix. O anti-Édipo: capitalismo e esquizofrenia. Trad.: Luiz B. L. Orlandi. São Paulo: Ed. 34, p. 560, (Coleção TRANS), 2010.

ELLIS, Albert. The Encyclopaedia of sexual behaviour: volume two. EUA: Heinemann Medical, p. 1060, 1961.

FEDERICI, Silvia. Calibã e a bruxa: mulheres, corpo e acumulação primitiva. Trad.: coletivo Sycorax. São Paulo: Elefante, p. 464, 2017

FOUCAULT, Michel. "Cap. IV. O dispositivo da sexualidade" in: História da Sexualidade I: A vontade do saber. Trad.: Maria Thereza da Costa Albuquerque e J. A. Guilhon. 13 ed. Rio de Janeiro, Edições Graal, 1988.

"O Corpo Utópico" in: O corpo utópico, as heterotopias. Posfácio: Daniel Defert. Trad.: Salma Tannus Muchail. 1 ed. São Paulo: n-1 Edições, p. 07-16, 2012. Albuquerque. Rio de Janeiro: Paz e Terra, p. 75-123, 2014. 
GABRIEL, Alice. "Ecofeminismo e ecologias queer: uma apresentação". Revista Estudos Feministas, Santa Catarina, v. 19, n. 1, p. 167-173, jan - abr, 2011.

HADOT, Pierre. Exercícios espirituais e filosofia antiga. Tradução de Flávio Fontenelle Loque e Loraine de Fátima Oliveira. São Paulo: É Realizações Editora, p. 368, 2014.

LEMON, George William. English Etymology Or A Derivative Dictionary Of The English Language: In Two Alphabets (1783). EUA: Kessinger Publishing, LLC. p. 668, 2009.

LEOPOLDO, Rafael. "Pelo cu: políticas anais.": por uma ética da passividade. Medium. Publicado em: 19.10.2016. Disponível em: https://medium.com/@ ralasfer/pelo-cu-pol\%C3\%ADticas-anais-por-uma\%C3\%A9tica-da-passividade-884fb5cf8140. Acesso em: 24 de ago. 2019.

LÉVY, Pierre. O que é o virtual. Trad.: Paulo Neves. 1 ed. São Paulo: Ed. 34, p. 160, (Coleção Trans). 1996.

LOYOLA, Maria Andréa. A antropologia da sexualidade no Brasil. Physis, Rio de Janeiro, v. 10, n. 1, p. 143-167, junho, 2000.

PRECIADO, Beatriz. Multidões queer: notas para uma política dos "anormais". Trad.: Cleiton Zóia Münchow e Viviane Teixeira Silveira. Revista Estudos Feministas, Santa Catarina, v. 19, n. 1, p. 11-20, jan. 2011.

PRECIADO, Paul B. Texto Junkie - sexo, drogas e biopolítica na era farmacopornográfica. Trad.: Maria Paula Gurgel Ribeiro com a contribuição de Verônica Daminelli Fernandes. Editora N-1, 2018.

RANCIÈRE, Jacques. A partilha do sensível. Tradução: Mônica Costa Netto. São Paulo: EXO experimental org.; Ed. 34, p. 72, 2005.

MaCKINNON, Catharine. "Desejo e poder" in: MIGUEL, L. Felipe, BIROLI, Flávia. Teoria Política Feminista: textos centrais. Vinhedo: Editora Horizonte, 2013, p. 231250 .

GONZALEZ, Lélia. A categoria político-cultural de amefricanidade. Tempo Brasileiro, Rio de Janeiro, No. 92/93, p. 69-82, jan./jun, 1988.

KRUL, A. J. ; EMMEL, R. A influência da Ciência do Positivismo Comteano no Pensamento Educacional Brasileiro. Revista de Ensino de Biologia da Associação Brasileira de Ensino de Biologia (SBEnBio), v. 1, p. 274-284, 2016. 
MISKOLCI, Richard. A teoria Queer e a sociologia: o desafio de uma analítica da normalização. Revista Sociologias, Porto Alegre, ano 11, n. 21, p. 150-182, jan/jun, 2009.

SILVEIRA, R. A brasileiríssima filosofia brasileira. Síntese, Belo Horizonte, v. 43, $\mathrm{n}^{\circ}$ 136, pp. 261-278, 2016.

PAIVA, Vera; ARANHA, Francisco; BASTOS, Francisco I. Opiniões e atitudes em relação à sexualidade: pesquisa de âmbito nacional, Brasil 2005. Rev. Saúde Pública, São Paulo, v. 42, supl. 1, p. 54-64, junho, 2008.

CARNEIRO, Aparecida Sueli. A Construção do Outro como Não-Ser como fundamento do Ser. Feusp, 2005. (Tese de doutorado).

CONTINENTINO, Ana Maria Amado. A Alteridade no pensamento de Jacques Derrida: Escritura, Meio-Luto, Aporia. 2006. 216p. (Tese de Doutorado).

SEXUALIDADE. Dicionário do Aurélio, 22.09.2018. Disponível em: <https://dicionariodoaurelio.com/sexualidade>. Acesso em: 22 de fev. 2019.

SEXUALIDADE. Dicionário Michaelis, 22.09.2018. Disponível em: <http://michaelis.uol.com.br/busca?id=vk0aV>. Acesso em: 22 de fev. 2019.

SEXUALITY. Cambridge Dicionary, 22.09.2018. Disponível em: $<$ https://dictionary.cambridge.org/pt/dicionario/ingles/sexuality>. Acesso em 22.02.2019. SEXUALITY. English Oxford Living Dictionaries, 22.09.2018. Disponível em: <https://en.oxforddictionaries.com/definition/sexuality>. Acesso em: 22 de fev. 2019.

SILVA, Ariana. Lésbicas negras, identidades interseccionais. Revista Periódicus, n.7, v.1, p. 117-133, maio-out; 2017. 